\title{
Detection of Nonlinear Spin Dynamics in Artificial Magnets Using Rectification of Planar Hall Effect
}

\author{
A. Yamaguchi*, K. Motoi, H. Miyajima, T. Uchiyama** and Y. Utsumi ${ }^{* * *}$ \\ Department of Physics, Keio University, 3-14-1 Hiyoshi Yokohama, Kanagawa 223-8522, Japan \\ * PRESTO, JST, 4-1-8 Honcho, Kawaguchi, Saitama 332-0012, Japan \\ ** Department of Electrical Engineering and Computer Science, Nagoya University, Chikusa, Nagoya, Aichi 464-8603, Japan \\ *** Laboratory of Advanced Science and Technology for Industry, University of Hyogo, 3-1-2 Koto, Ako, Hyogo 678-1205, Japan
}

\begin{abstract}
We have investigated the dynamics of a vortex core trapped in a single layered Fe19Ni18 disk. The large amplitude excitation of the vortex core translational mode causes a shift in the resonance frequency. We can explain the self-bistable mode where the position and amplitude of a dynamic vortex core determines the translational mode effect on the dynamic change of the gradient of the potential well. The phenomenological model that describes the self-bistability also provides an explanation for the asymmetrical spectrum shape. The self-bistability to tune the resonance using the input current would be extremely useful for high-frequency devices. This work also opens up a rich new area of study in the field of nano-scale magnets.
\end{abstract}

Key words: vortex, planar Hall effect, rectification, non-linear resonance

\section{プレナーホール整流効果を用いた人工磁性体の非線形応答の検出 \\ 山口明啓*・元井桂一・宮島英紀・内山剛"**内海裕一**** \\ 慶應義塾大学理工学部物理学科, 横浜市港北区日吉 3-14-1（广223-8522） \\ "JST さきがけ，埼玉県川口市本町 4-1-8（テ332-0012） \\ " 名古屋大学大学院工学研究科電子情報システム専攻, 名古屋市千種区不老町 (厂464-8601) \\ ***兵庫県立大学高度産業科学技術研究所, 兵庫県赤穂郡上郡町光都 3-1-2（予678-1205）}

\section{1. はじめに}

形状が制御された薄膜ソフト磁性体では，スピン波が境界条件 により量子化・局在化することが良く知られており，スピンの動 的挙動を理解寸る格好の研究対象であることから興味をもたれて いる ${ }^{1,2)}$.また，形状制御された人工磁生体は，高周波機能性素子 などの新しい応用技術一の展開の可能性をもっている. 特に, 最 近, 磁気状態を電流によって制御できることが発見され ${ }^{3-12), ~}$ 電流

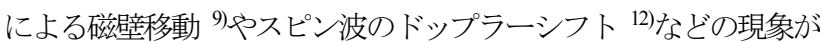
注目されている

ソフト磁性体の形状を円盤形状にすると，磁気渦構造が形成さ れる ${ }^{13-15)}$. 磁父渦の旋回運動を高周波電流と外部磁場印加によっ て励起し, 磁気渦の磁化反転を操作できることが最近報告され ${ }^{10}$, 不揮発性磁気メモリなどへの応用に期待が寄せられている。しか し, ナノスケールあるいはマイクロスケールの単一人工磁性体中 に形成される磁気渦状態の動的挙動を明らかにすることは容易で はない，本研究では，磁気渦の動的挙動を電気的に高感度に検出 し 17, 18)，その動的挙動から出現する電気信号について拡張した Thiele方程式を用いて説明できることを定性的に示寸.

\section{2. 実験手法と試料作製}

磁気渦の検出は，プレナーホール配置における高周波電 流の整流効果を用いる ${ }^{17,18)}$. この検出方法には, 高周波電 流の電流分布がホール電極によって変化する可能性がある 欠点を有しているが，ホール電極を小さく絞ってホール測 定回路のインピーダンスを大きくすることによって，影響
を出来るだけ小さくすることが可能である．実際に，強磁 性細線のプレナーホール効果の測定結果では，ホール電極 の影響は多少あるにしても，現象の本質に影響を与える程 度ではないことが分かっている ${ }^{17)}$. 加えて，本測定で用い た周波数帯域が数十 $\mathrm{MHz}$ 程度と狭いために大きな問題と ならない。一方, この検出方法の利点は, 直流電流を高周 波電流に重畳して入力した際に生じる試料抵抗の温度変化 の寄与を抑制できるので，検出信号のバックグランドの時 間変動を抑制できることである ${ }^{17)}$. なお，通常の異常磁気 抵抗効果を利用した整流効果検出においても，ホイットー ンストーン・ブリッジ等を用いたゼロ点検出方法によって 直流電流と高周波電流との応答特性を分離して検出寸るこ とが可能である。しかし，ブリッジ回路の特性や磁性体の 温度上昇など外的な環境に左右され，本質的ではない信号 を分離するために苦労することが多い，本手法は，上述し た欠点を補って余りある検出手法となる ${ }^{17,18)}$.

今回の実験に用いた試料の光学顕微鏡像ならびに測定回路の模 式図を Fig. 1 亿示寸. 試料は $\mathrm{MgO}$ 基板上に電子線リソグラフィー とリフトオフ法を用いて作製した. ナノ磁性体には厚み $30 \mathrm{~nm}$, 半 径 $3 \mu \mathrm{m}$ の $\mathrm{Fe}_{19} \mathrm{Ni}_{81}$ を用い，コプレナーガイドの中心信号線内に配 置した. 直流電流源をバイアス $\mathrm{T}$ に接続し, 高周波電流と直流電 流を重畳して試料に入力する. 高周波電流を信号発生器から入力 して, 周波数を掃引しながらプレナーホール電圧を測定する. 外 部静磁場はコプレナーガイドの中心信号線から角度 $\phi$ の方向から 面内で印加する，測定はすべて室温，大気中でおこなった. 


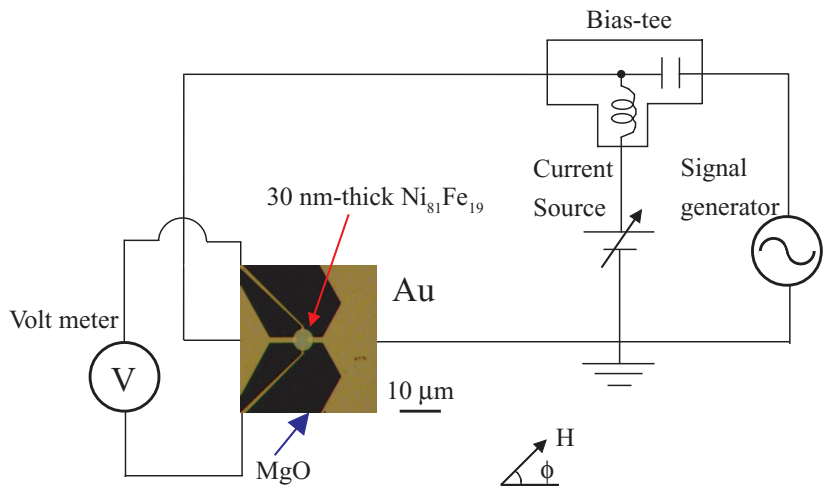

Fig. 1 Optical micrograph of a fabricated sample and schematic of measurement circuit setup.

\section{3. 実験結果}

\section{1 磁場依存性}

直流電流を入力せず，高周波電流-4 $\mathrm{dBm}$ を入力した際の プレナーホール電圧整流スペクトルの外部磁場依存性を Fig. 2(a)に示す. このときの電流密度は, $(1.0-2.0) \times 10^{10}$ $\mathrm{A} / \mathrm{m}^{2}$ と見積もった。 ここでは, 磁気円盤は空間的に一様で はないので, 電極のサイズと磁気円盤の直径から電流密度 を算出した。また，このとき，スピン偏極電流のみで無磁 場下で期待される旋回運動モード(Translational mode)の軌 道半径は, 文献 15 から約 $100 \mathrm{~nm}$ 程度である. 外部静磁場 は, 電流入力方向からの角度 $\phi=90^{\circ}$ 方向に印加した. 外部 磁場の方向は, $\phi=90^{\circ}$ を方向とし, $\phi=270^{\circ}$ 方向を一方 向とする. Fig. 2(a)の結果から, 外部磁場が大きく磁気渦が 存在しない単一磁区構造を形成している際には, 整流スペ クトルには目立った変化は見られない ${ }^{18)}$. 一方，外部磁場 を小さくし，磁気渦が生成した状態では共鳴スペクトルが 観測された。これは, 磁気渦の旋回運動モードに対応する 共鳴スペクトルである ${ }^{18)}$. 外部磁場の印加に伴って, 共鳴 周波数が低減していくことが分かった.

さらに逆方向に外部磁場強度を増加させていくと, $24 \mathrm{Oe}$ の時に非常に複雑なスペクトルとなり，35 Oe では符号が 反転している．これは，磁気渦が磁気円盤から押し出され て磁気構造が変化し, 外部磁場と高周波電流による復元力 のために磁気渦が磁気円盤内に戻って磁気構造が変化した ことに起因するプレナーホール電圧であると考えられる. その際，磁気円盤全体に亘って，磁気構造の空間的・時間 的再配列が起きるため, 伝導電子がベリ一位相を獲得しス ピン起電力の発生の可能性も示唆される ${ }^{19-21)}$. しかし, 現 時点ではスピン起電力とプレナーホール電圧を区別するこ とができないため, 直流電圧スペクトルが磁気構造に起因 することについて言及する.

無磁場中では, 磁気渦が磁気円盤中心付近に存在してい るので, 直流電圧スペクトルは対称であるが，外部磁場が $18 \mathrm{Oe}$ では非対称なスペクトルになっていることが Fig. 2(a) ならびに Fig. 2(b)から明らかである. この理由は, 磁気渦
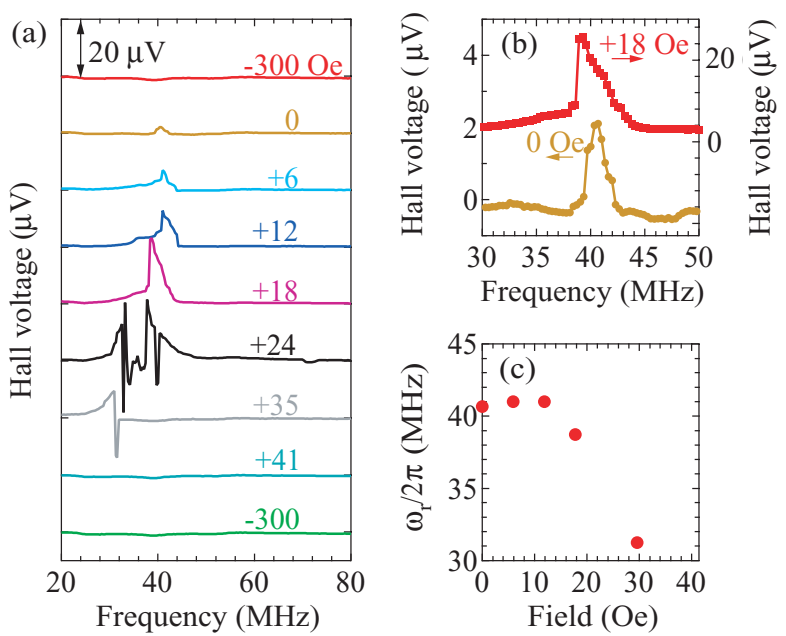

Fig.2 (a) Rectifying planar Hall voltage generated by the $\mathrm{Fe}_{19} \mathrm{Ni}_{81}$ disk ( $30 \mathrm{~nm}$ thick and $3 \mu \mathrm{m}$ in radius) in response to the rf current without dc current under decreasing external magnetic field. Each spectrum is vertically shifted for clarity. (b) Comparison of the spectrum in 18 and 0 Oe. (c) Resonant frequency $\omega_{\mathrm{r}}$ as a function of the applied field.

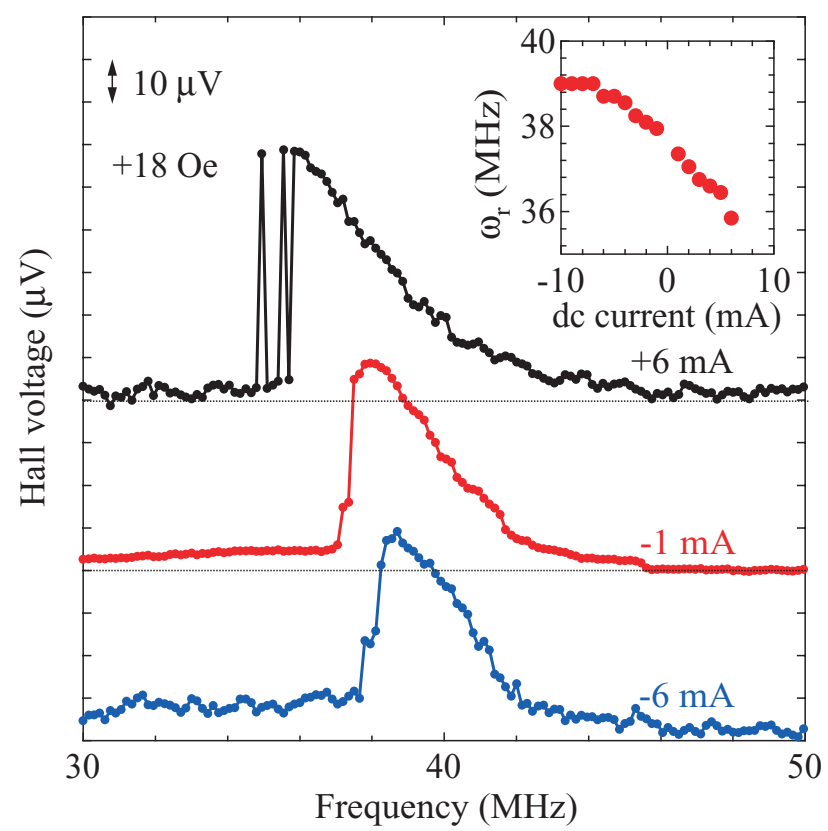

Fig. 3 Rectifying Hall voltage spectra measured in 18 Oe with a series of $\mathrm{dc}$ current applications. The inset shows the dependences of resonant frequency $\omega_{\mathrm{r}}$ on dc current.

の旋回運動が中心部分からずれた位置で行われる場合, 空 間的に対称な軌道にならないためと考えられる。また，こ のとき信号強度は無磁場下の信号強度に比べて約 10 倍に なっていることから, 軌道半径もそれに対応して約 10 倍大 きくなっているものと考えられ，従来の理論的・現象論的 な解析を見直す必要があると考えられる.

また, Fig. 2(c)には共鳴周波数の外部磁場依存性を示した. 
共鳴周波数は磁気渦の位置の関数として与えられる.

\section{2 直流電流印加によるスペクトルの変化}

高周波電流に直流電流を重畳したときのプレナーホール 電圧整流スペクトルを Fig. 3 に示す. 外部磁場は, 18 Oe と固定した。直流電流を入力した際に，スペクトルのベー スラインが変化するが，今回の物理現象には本質的ではな いので, ベースラインをそろえてスペクトルを表示してい る. 直流電流の入力に伴って, 共鳴周波数のシフトとスペ クトル形状は対称から非対称になる。特に+6 mA を印加し た場合には，非対称なスペクトル形状になるばかりか，急 激なスパイク状の変化が低周波側に出現している.

\section{4. 解析と議論}

以上のように直流電流の印加に伴って, 整流スペクトル の非対称性の大小が変化する。このような現象が，どのよ うな機構によって起きるのかを考察する．外部磁場や直流 電流など静的な作用を加えない場合, 磁気渦は磁気円盤中 心付近に存在する。その時，磁気渦は近似的には放物線型 のポテンシャル井戸の底に存在している ${ }^{13,14)}$. このとき, 高周波電流を印加すると，高周波磁場とスピントルクによ つて放物線型ポテンシャル底の中心付近で運動を行う。そ の運動は次式のような拡張された Thiele 方程式 13, 14, 22, 23, 24) によく従う。

$$
\boldsymbol{G}(p) \times(\boldsymbol{u}-\dot{\boldsymbol{r}})=-\frac{\delta U(\boldsymbol{r})}{\delta \boldsymbol{r}}-\alpha D \dot{\boldsymbol{r}}+\beta D \boldsymbol{u},
$$

ここで $\boldsymbol{G}(p)=-G_{0} p \hat{\boldsymbol{z}}, G_{0}=2 \pi L M_{\mathrm{S}} / \gamma, p$ は磁気渦中 心が上向きか下向きかを決定する polarity である， $L, M_{\mathrm{S}}$ ならびに $\gamma$ は磁気円盤の厚さ, 飽和磁化, ジャイロ磁気回 転比である.さらに， $\boldsymbol{u}$ は磁気モーメントと電流の相互作 用に起因するスピントルク項であり， $\boldsymbol{u}=\left(\mu_{\mathrm{B}} \boldsymbol{J} P / e M_{\mathrm{S}}\right)=u_{0} \hat{\boldsymbol{x}}$ と与えられる ${ }^{3-7)}$. 今, 実験結果と 対応させるために, 電流を $\hat{\boldsymbol{x}}$ 軸に沿って流れている.また, $\boldsymbol{J}$ : 電流密度, $e$ : 電子の素電荷, $P$ : スピン分極率, $\alpha$ : ギルバート・ダンピング定数, $\beta$ : 非断熱的スピントルクに よる寄与として与えられるパラメータならびに $D$ : ダン ピング・テンソルである.

今, 磁気渦が円盤内の平衡位置 $\left(x_{0}, y_{0}\right)$ の周りを回転運動 していると考える. その際，先述したようにポテンシャル $U(\boldsymbol{r})$ は近似的に

$$
U(\boldsymbol{r})=\kappa_{x}\left(x-x_{0}\right)^{2} / 2+\kappa_{y}\left(y-y_{0}\right)^{2} / 2,
$$

と与える ${ }^{14,23,24)}$. ここで， $\kappa_{x(y)}$ は静磁エネルギ一や交換エ ネルギーから決定される有効スティフネス係数であり，磁 気渦の位置に変化する。この平衡位置の周りで高周波電流 によって磁気渦が共鳴振動をおこした場合, 共鳴周波数は,

$$
\omega_{\mathrm{r}}=\frac{\sqrt{q_{x} q_{y}}}{1+\tilde{\alpha}^{2}},
$$

となる。ここで,,$q_{x(y)}=\kappa_{x(y)} / G_{0}$, $\tilde{\alpha}=\alpha D / G_{0}, \tilde{\beta}=\beta D / G_{0}$ ならびに $\alpha^{*}=\tilde{\alpha}\left(q_{x}+q_{y}\right) /\left(1+\tilde{\alpha}^{2}\right)$ である ${ }^{24)}$. さらに, その振幅 $A=\sqrt{X^{2}+Y^{2}}$ は

$A^{2}=\frac{u_{0}^{2}\left[\left(\tilde{\beta}^{2} q_{y}^{2}+q_{x}^{2}\right)+\omega^{2}\left\{(1+\tilde{\alpha} \tilde{\beta})^{2}+(\tilde{\beta}-\tilde{\alpha})^{2}\right\}\right]}{\left(1+\tilde{\alpha}^{2}\right)^{2}\left[\left(\omega_{\mathrm{r}}^{2}-\omega^{2}\right)^{2}+\left(\omega \alpha^{*}\right)^{2}\right]}$.

で与えられる，磁気円盤中心付近では，(4)式はローレンツ 型の共鳴スペクトルを与え，文献 15 と一致する。また，口 ーレンツ型の共鳴スペクトルは，これまでの多くの報告で 観測されている ${ }^{14,15)}$. 軌道半径の共鳴形状は，磁化の動的 挙動と一対一で対応しており, 異方性磁気抵抗効果やプレ ナーホール電圧を含む電流磁気効果テンソルによって, プ レナーホール電圧のスペクトル形状と結びついている ${ }^{17)}$.
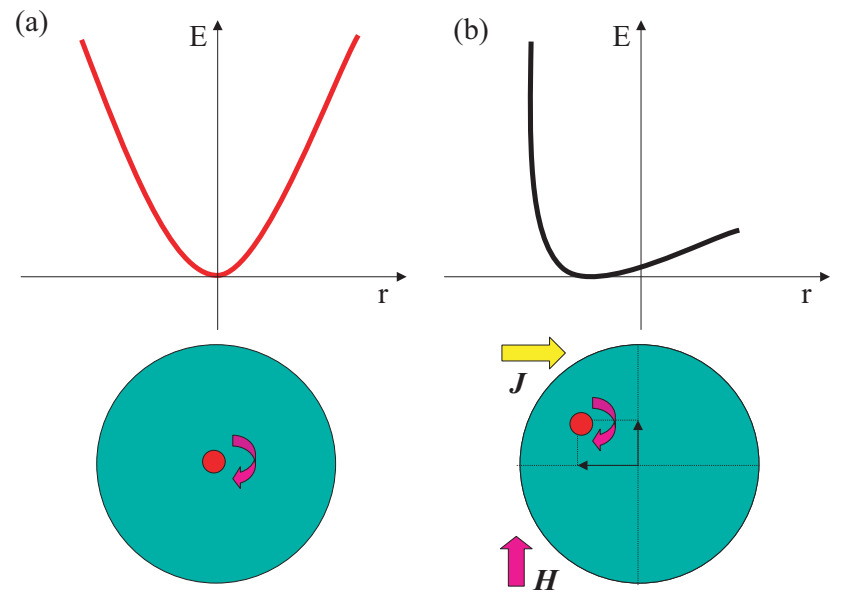

Fig. 4 Schematic potential energy profiles as a function of vortex core position for (a) the absence of static field and (b) application of both static field and current.

次に，外部磁場や直流電流を印加したときを考える。こ のとき，磁気渦は外部からの静的作用によって円盤中心か ら離れた位置を平衡位置として, その周りを運動すること になる．このとき，ポテンシャル勾配 $q_{x(y)}$ が変化している ので，ポテンシャルの形状は模式的には Fig. 4(a)から Fig. 4(b)のように変化することに対応する ${ }^{14)}$.これは，ポテン シャル形状の展開(2)式に, 4 次の項を導入し, 復元力とし て 3 次の調和振動子で記述されることに対応する.さらに, 高周波電流を大きくすると，共鳴振幅が大きくなり，周波 数が変化する．このことは，強励起状態であることが高次 のポテンシャル勾配による影響を強めていることに対応す る. それに伴い, 系全体として, ポテンシャル勾配 $q_{x(y)}$ が 変化し, 共鳴周波数は, (3)式に従って変化している.また, 外部磁場や直流電流によって, 磁気渦の旋回運動中心が磁 気円盤中心付近から離れた平衡位置でも周波数が変化する. このような現象は Fig. 2 と Fig. 3 に示された実験結果にお 
いて, すでに測定されている. そこで, 共鳴周波数変化 $\Delta \omega$ は, 位置 $\boldsymbol{r}_{0}=\left(x_{0}, y_{0}\right)$ と振幅 $A$ の関数で与えられるが，こ こでは近似的に $\Delta \omega$ は $A$ に比例すると仮定して $\Delta \omega=\eta A$ （ $\eta$ は比例定数）と与える. この置換は, 高次のポテンシ ヤルを導入した拡張された Thiele 方程式の近似解に対応し ているものと考えられる. 周波数変化 $\Delta \omega$ を与えた時に, (4)式の振幅は以下のように

$$
A^{\prime 2}=\frac{u_{0}^{2}\left[\left(\tilde{\beta}^{2} q_{y}^{2}+q_{x}^{2}\right)+\omega^{2}\left\{(1+\tilde{\alpha} \tilde{\beta})^{2}+(\tilde{\beta}-\tilde{\alpha})^{2}\right\}\right]}{\left(1+\tilde{\alpha}^{2}\right)^{2}\left[\left\{\left(\omega_{\mathrm{r}}^{2}+\eta A^{\prime}\right)^{2}-\omega^{2}\right\}^{2}+\left(\omega \alpha^{*}\right)^{2}\right]} .
$$

ここで，振幅も変化することになるので，(4)式と区別す るために振幅を $A^{\prime}$ とした。この(5)式は, 振幅 $A^{\prime}$ について の 6 次方程式になっている. 共鳴周波数を与え, それとは 異なる周波数での入力 $u_{0}$ に対する振幅 $A^{\prime}$ を Fig. 5(a)に示 した. 6 次方程式であるので， ある領域で一定の入力に対 して 6 つの解が存在するが，この領域で状態が準安定状態 を行き来する（Fig. 5(a)）。この準安定状態とは，渦中心が 安定して旋回運動を出来る軌道状態であり，渦中心が旋回 中に軌道を変えることに対応する．このような現象ならび に解析は, Stancil や Patton らによって理論的説明が与えら れ ${ }^{25)}$, フェライトの強磁性共鳴状態で観測されている ${ }^{26)}$. フェライト系では準安定状態が区別されているが，磁気渦 の場合は，渦中心の動的挙動によってエネルギー状態が時 間とともに変化していることに起因する.このような振る 舞いを総称して, self-bistabilityという.

入力電流を変化させたときの振幅 $A^{\prime}$ の周波数依存性を Fig. 5(b)に示す. 周波数シフトを決定するパラメータ $\eta$ の符 号は, 実験結果に合わせて負としている. Fig. 3(b)に示した ように，入力を大きくすると共鳴周波数が低周波側に移動 し，振幅のスペクトル形状は対称的なローレンツ型形状か ら非対称形状へ変化する. 磁気渦の振幅が変形するとプレ 一ナーホール効果を通じて整流スペクトルに非対称性を生 じる ${ }^{17)}$. すなわち，この解析結果は, Fig. 2 ならびに Fig. 3 の実験結果と定性的に一致している.

この self-bistabilityを利用した電気的検出方法を発展させ ることによって, 磁気円盤の chirality ならびに polarity の縮 退状態の検出が可能になることが期待できる. 以上のよう に, 異方性磁気抵抗効果ならびにプレナーホール効果の整 流作用と self-bistability によって, 電気的に簡便にナノスケ 一ルあるいはマイクロメートルスケールの人工磁性体中の 磁化ダイナミクスの解明が定量的に測定できるようになる ものと期待できる.

\section{5. まとめ}

磁気円盤における磁気渦の動的挙動について，プレナー ホール電圧の整流効果を用いて検出することに成功した. 外部静磁場だけではなく, 直流電流印加によっても, 共鳴
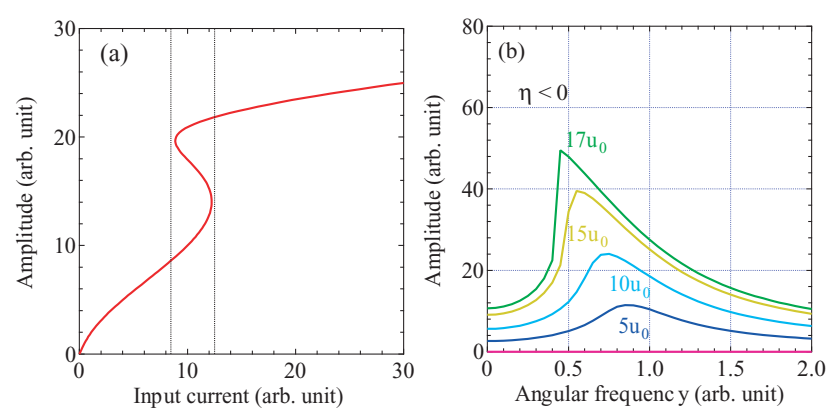

Fig. 5 (a) Estimated response of a magnetic disk. (b) Simulated asymmetric spectra in translational mode response of the magnetic disk.

周波数を変調し，スペクトル形状が対称から非対称な構造 に操作することができることを示した．この現象は，磁気 渦中心の動的挙動そのものが作り出す self-bistabilityによる 効果であることが実験結果と解析モデルから説明できた. 微小人工磁性体の基本的な物理の理解をこの電気的な手法 で,さらに深めていくことが期待される.また，共鳴周波 数や半值幅を電流で制御できることから，新しい機能性素 子としての応用についても期待される.

謝辞 本研究の一部は, 科学研究補助金基盤研究(A),基盤 研究(B)および戦略的創造研究推進事業さきがけプログラ ムにより支援された.

\section{References}

1) B. Hillebrands and K. E. Ounadjela (Eds): Spin Dynamics in Confined Magnetic Structures, vol. I (Springer, Berlin, Heidelberg 2002).

2) C. Bayer, S. O. Demokritov, B. Hillebrands, and A. N. Slavin: Appl. Phys. Lett. 82, 607 (2003); C. Bayer, J. Jorzick, B. Hillebrands, S. O. Demokritov, R. Kouba, R. Bozinoski, A. N. Slavin, K. Y. Guslienko, D. V. Berkov, N. L. Gorn, and M. P. Kostylev: Phys. Rev. B 72 , 064427 (2005); S. O. Demokritov, B. Hillrbrands, and A. N. Slavin: Phys. Rep. 348, 441 (2001).

3) J. C. Slonczewski, J. Magn. Magn. Mater.: 159, L1 (1996).

4) L. Berger: Phys. Rev. B 54, 9353 (1996).

5) G. Tatara and H. Kohno: Phys. Rev. Lett. 92, 086601 (2004).

6) S. Zhang and Z. Li: Phys. Rev. Lett. 93, 127204 (2004).

7) A. Thiaville, Y. Nakatani, J. Miltat, and Y. Suzuki, Europhys. Lett. 69, 990 (2005).

8) J. A. Katine, F. J. Albert, R. A. Buhrman, E. B. Myers and D. C. Ralph, Phys. Rev. Lett. 84, 3149 (2000).

9) A. Yamaguchi, T. Ono, S. Nasu, K. Miyake, K. Mibu and T. Shinjo, Phys. Rev. Lett. 92, 077205 (2004).

10) J. Shibata, G. Tatara, and H. Kohno, Phys. Rev. Lett. 94, 076601 (2005).

11) Y. Nakatani, J. Shibata, G. Tatara, H. Kohno, A. Thiaville, and J. Miltat, Phys. Rev. B 77, 014439 (2008).

12) V. Vlaminck and M. Bailleul, Science 322, 410 (2008).

13) K. Yu. Guslienko, B. A. Ivanov, V. Novosad, H. Shima, Y. Otani and K. Fukamichi: J. Appl. Phys. 91, 8037 (2002). 
14) K. S. Buchanan, P. E. Roy, M. Grimsditch, F. Y. Frandin, K. Yu. Guslienko, S. D. Bader and V. Novosad: Phys. Rev. B 74, 064404 (2006). 15) S. Kasai, Y. Nakatani, K. Kobayashi, H. Kohno and T. Ono: Phys. Rev. Lett. 97, 107204 (2006); S. Kasai, P. Fischer, M. -Y. Im, K.Yamada, Y. Nakatani, K. Kobayashi, H. Kohno and T. Ono, Phys. Rev. Lett. 101, 237203 (2008).

16) K. Yamada, S. Kasai, Y. Nakatani, K. Kobayashi, H. Kohno, A. Thiaville and T. Ono: Nat. Mat. 6, 269 (2007).

17) A. Yamaguchi, K. Motoi, A. Hirohata and H. Miyajima: Phys. Rev. B 79, 224409 (2009).

18) A. Yamaguchi, K. Motoi, H. Miyajima, A. Hirohata, T. Yamaoka, T. Uchiyama and Y. Utsumi: Appl. Phys. Lett. 95, 122506 (2009).

19) S. E. Barnes and S. Maekawa: Phys. Rev. Lett. 98, 246601 (2007).

20) J. Shibata and H. Kohno: Phys. Rev. Lett. 102, 086603 (2009).

21) J. -I. Ohe, S. E. Barnes, H. -W. Lee and S. Maekawa: Appl. Phys. Lett. 95, 123110 (2009).

22) A. A. Thiele: J. Appl. Phys. 45, 377 (1974).

23) J. Shibata, Y. Nakatani, G. Tatara, H. Kohno and Y. Otani: Phys. Rev. B 73, 020403(R) (2006).

24) R. Moriya, L. Thomas, M. Hayashi, Y. B. Bazaliy, C. Rettner and S. S. P. Parkin: Nat. Phys. 4, 368 (2008).

25) A. Prabhakar and D. D. Stancil: J. Appl. Phys. 85, 4859 (1999).

26) Y. K. Fetisov, C. E. Patton and V. T. Synogach: IEEE Trans. Magn. 35, 4511 (1999)

\section{9年10月7日受理，2010年1月14日採録}

